\title{
PSYCHOLOGICAL DISTRESS IN CANCER PATIENTS WITH UNDERAGE CHILDREN
}

\author{
AKTER J ${ }^{1}$, KHAN JG ${ }^{2}$, KHAN MH ${ }^{3}$, HOSSAIN MZ ${ }^{4}$
}

\begin{abstract}
:
Context: A cross-sectional comparative study was designed to compare psychological distress in cancer patients with and without minor children.

Materials and methods: This study was done to compare anxiety and depression status among the cancer patients attending at National Institute of Cancer Research Hospital, Oncology department in Dhaka Medical College Hospital and in Uttara Adhunik Medical College Hospital. The study was conducted from September, 2012 to June, 2013. Respondents had been divided into two groups. In study group 123 cancer patients having underage children were included and in comparison group 116 cancer patients without having underage children were selected. Purposive sampling was applied. All the married cancer patients in both groups were selected randomly each between the age from 20 to 60 years with minimal or no physical difficulties. They did not have any history of prior psychiatric illness or co morbidities or substance abuse related to development of secondary psychiatric disorders. Distress among the patients were measured with the Hospital Anxiety and Depression Scale (Two sub scales - A - Anxiety subscale and D - Depression subscale).
\end{abstract}

Result: In the study group, 60.2\% respondents were male and 39.8\% female. And in comparison group male and female were $42.2 \%$ and $57.8 \%$. Mean age of the participants in study group was $36.97 \pm 4.37$ and in comparison group was $42.98 \pm 11.74$ years. The mean duration since diagnosis was $12.85 \pm 13.11$ months in study group and $11.53 \pm 6.72$ months in comparison group. Majority of the respondents in study group were suffering from guynaecological cancer (25.2\%) and gastro intestinal cancer (25.2\%). Majority cancer in comparison group were guynaecological cancer (31\%) and haematolymphoid cancer (20.7\%) as well. Metastasis was present in $42.3 \%$ patients in study sample and $35.3 \%$ patients in comparison group. In study group $99.2 \%$ patients were suffering from both anxiety and depression. Majority (79.3\%) patients in comparison group had been found depressed and $70.7 \%$ of them were anxious also. In study group $48.8 \%$ had moderate anxiety, 39\% had severe and $11.4 \%$ had mild anxiety. Only $0.8 \%$ cancer patient had normal anxiety in this group. In comparison group 29.3\% patients were normal in this regard. Majority (64.7\%) had mild anxiety, 6\% had moderate and no one had severe anxiety. Anxiety status was significantly different between the groups ( $p<0.001)$. Majority of the cancer patients in study group were suffering from depression. In this group $45.5 \%$ had moderate, $37.4 \%$ had severe, $16.3 \%$ had mild depression. In comparison group $62.1 \%$ had mild, $20.7 \%$ normal, $16.4 \%$ moderate and $0.9 \%$ had severe depression. The groups were significantly different $(p<0.001)$ in depression status. In study group mean anxiety score in male was $15.72 \pm 2.314$ and in female was $12.06 \pm 2.802$, i.e. father with minor children were suffering from more anxiety than the mother $(t=7.878, p<0.001)$. Mean depression score in male in study group was $11.91 \pm 2.489$ and in female was $17.55 \pm 2.542$, i.e. female cancer patients with minor children were found more depressed than male $(t=12.211$; and $p<0.001)$.

Conclusion: Almost all of the cancer patients with minor children had been found psychologically distressed. Cancer father with minor children were more prone to development of higher anxiety than the mothers in the same group. Female cancer patients with minor children were found more depressed than male.

Key words: Psychological distress, cancer patients, underage children, gender.

J Dhaka Med Coll. 2015; 24(2) : 146-151.

1. Dr. Jamila Akter, Lecturer, Dept. of Community Medicine, Uttara Adhunik Medical College

2. Dr. Jaglul Gaffer Khan, Assistant Professor, Paediatric Surgery, Dhaka Medical College Hospital

3. Dr. Manzurul Haque Khan, Assistant Professor, Occupational and Environmental Health, National Institute of Preventive and Social Medicine (NIPSOM) Mohakhali, Dhaka

4. Dr. Mohammad Zaid Hossain, Associate Professor of Medicine, Dhaka Medical College.

Correspondence: Dr. Jamila Akter, Lecturer, Dept. of Community Medicine, Uttara Adhunik Medical College. Cell Phone: 8801718358762, E-mail: jamilaakter161@gmail.com 


\section{Introduction}

Emotional distress has been found as a core indicator of a patient's health, well-being and has installed it as the sixth vital sign ${ }^{1}$. Anxiety and depression are the most common psychological problems in cancer patients ${ }^{2}$.An estimated $22.4 \%$ of cancer cases occur in individuals between 21 and 55 years of age $^{3}$. These are prime childbearing and parenting years, so a substantial proportion of survivors in this age range may have minor children. Cancer and its treatment pose unique challenges to survivors with minor children and may have a more negative impact on these individuals and their families, compared to survivors without children or those with adult children. Cancer diagnosis and treatment has considerable impact on the parents having minor children. Distress and functioning may vary depending on gender of the parent with cancer as well.

When a parent receives a diagnosis of cancer, it is acknowledged in the literature that the demands of this illness add to the normal challenges of parenting ${ }^{4}$. Being diagnosed with a life threatening disease such as cancer induces a new situation in life which requires adjustment a lot. Studies confirm that about a third of newly diagnosed cancer patients develop clinically significant psychological distress. At a time when many wish to be engaged emotionally with loved ones, these disturbances decrease patients $1 / 4$ emotional, social and cognitive function. Mental health is indispensable to personal wellbeing, family wellbeing and interpersonal relationships. Clinical anxiety has been observed in 15-30\% of cancer patients and depression in $20-25 \% 5$. In the diagnostic phase, adjustment disorders with anxious and depressive mood are seen in about $30 \%$ of cases, but major depression or other severe psychological symptoms are not common in this period ${ }^{6}$. Currently it is consensual that approximately one third of all oncology patients experience significant level of emotional distress associated with cancer diagnosis and treatment and which warrants psychological treatment ${ }^{7}$.

\section{Methodology}

A cross sectional comparative study was conducted among cancer patients in National Institute of Cancer Research Hospital, Oncology department of Dhaka Medical College Hospital and Uttara Adhunik Medical College Hospital. Only the married cancer parents were included. The study group had underage children (child below 18 years of age) and the comparison group had no underage children. All the study population were asymptomatic or minimally symptomatic cancer patients on active anticancer treatment. The patients were recruited from the hospital during their ambulant treatment or follow-up. They had no history of prior psychiatric illness or neurological diseases (i.e. parkinson $1 / 4 \mathrm{~S}$ disease, huntington $1 / 4 \mathrm{~S}$ disease, ceribrovascular accidents, multiple sclerosis and alzheimer $1 / 4$ disease). Selected medical illnesses were excluded (i.e. cushing $1 / 4 \mathrm{~S}$ syndrome, type I/type II diabetes mellitus, end stage renal disease and coronary heart disease). In study group 123 cancer parents were selected, while in comparison group 116 parents were included with the purposive sampling technique. Direct face to face interview had done and available hospital records had examined. Interviewer administered semi structured questionnaire was used for collection of data. The questionnaire included demographic information, clinical information and distress measuring questions. Demographic and medical data had been obtained from the participants and from their medical records. Psychiatric assessment had done with the questionnaire according to HADS-D (A version of 14 items Hospital Anxiety and Depression Scale). The HADS-D separately measures anxiety and depression in adults with physical illness. The scale comprises 14 statements relevant to either generalized anxiety (7 statements) or depression (again 7 statements) which the patient rates based on their experience over the past week. After processing and cleaning, data was analyzed with SPSS 19.0. Descriptive statistics as well as the comparative tests were used to characterize the variables and associations. t-tests had been used for continuous variables and $x^{2}$ (chisquare) statistics had been used for binary variables.

\section{Result}

Age of the respondents varied from 20 to 60 years. Mean age in study group was $36.97 \pm 4.37$ and in comparison group was $42.98 \pm 11.76$ years. Males accounted for $60.2 \%$ respondents in study group and $42.2 \%$ in comparison group. $84.6 \%$ cancer patients with minor children were married and rest were widow/divorced/ separated. In group having no underage children, $78.4 \%$ were married. 
Table I

Demographic characteristics of cancer patients.

\begin{tabular}{lcccc}
\hline Characteristics & Study group $^{*}$ & Comparison group $^{*}$ & $x^{2}$-value & $p$-value \\
\hline Age group (in years) & & & & \\
$\quad 20-39$ & $68(55.3)$ & $39(33.6)$ & 11.331 & 0.001 \\
$\quad 40-60$ & $55(44.7)$ & $77(66.4)$ & & \\
Sex & & & & \\
$\quad$ Male & $74(60.2)$ & $49(42.2)$ & 7.676 & 0.006 \\
$\quad$ Female & $49(39.8)$ & $67(57.8)$ & & \\
Marital status & & & & \\
$\quad$ Married & $104(84.6)$ & $91(78.4)$ & 27.256 & $<0.001$ \\
$\quad$ Widow/divorced/ Separated & $19(15.4)$ & $25(21.6)$ & & \\
\hline
\end{tabular}

*Percentage in parenthesis

It was observed that majority participants in both groups had suffered from guynaecological cancer; $25.2 \%$ in study group and $31 \%$ in comparison group. $2^{\text {nd }}$ major type was gastrointestinal cancer in study group and haematolymphoid cancer in comparison group. Type of cancer was significantly different between the groups $(\mathrm{p}<0.05)$.

Table-II

Type of cancer.

\begin{tabular}{lcccc}
\hline Type of cancer & Study group $^{*}$ & Comparison group $^{*}$ & $\chi^{2}$-value & p-value \\
\hline Guynaecological & $31(25.2)$ & $36(31)$ & & \\
Gastrointestinal & $31(25.2)$ & $21(18.1)$ & & \\
Haematolymphoid & $9(7.3)$ & $24(20.7)$ & & \\
Oropharyngeal & $18(14.6)$ & $9(7.8)$ & 13.159 & 0.041 \\
Lung & $13(10.6)$ & $11(9.5)$ & & \\
Genitourinary & $16(13.0)$ & $12(10.3)$ & \\
Other & $5(4.1)$ & $3(2.6)$ & & \\
\hline
\end{tabular}

*Percentage in parenthesis

The two groups were not significantly different with the distribution of disease duration $(\mathrm{p}=$ 0.333 ). Mean duration since diagnosis of cancer was $12.85 \pm 13.107$ months in study group and $11.53 \pm 6.716$ months in comparison group.

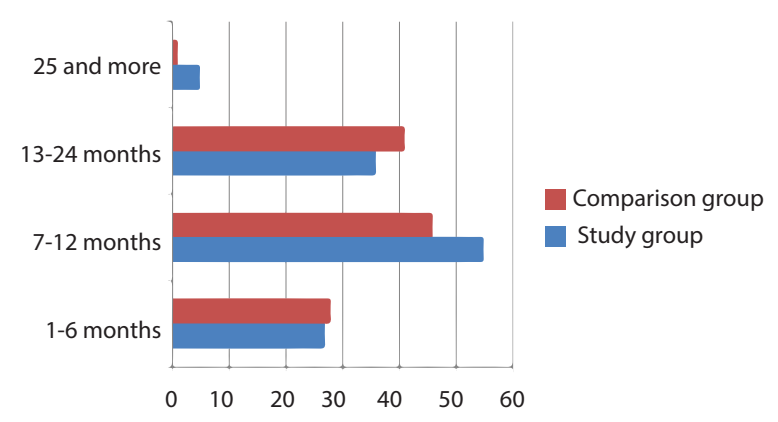

Fig.-1: Duration since diagnosis of cancer in both groups.
Metastasis was absent in majority (57.7\%) of respondents in study group. In other group $64.7 \%$ had no history of metastasis as well.

Table III

Distribution of metastasis of cancer

\begin{tabular}{lcr}
\hline $\begin{array}{l}\text { Metastasis } \\
\text { present }\end{array}$ & $\begin{array}{c}\text { Study } \\
\text { group (\%) }\end{array}$ & $\begin{array}{r}\text { Comparison } \\
\text { group (\%) }\end{array}$ \\
\hline Yes & $52(42.3)$ & $41(35.3)$ \\
No & $71(57.7)$ & $75(64.7)$ \\
\hline Total & $123(100)$ & $116(100)$ \\
\hline
\end{tabular}


Psychological distress (anxiety and depression) was more prevalent in study group. In study group $99.2 \%$ patients were suffering from both anxiety and depression. Majority (79.3\%) patients in comparison group had been found depressed and $70.7 \%$ of them were anxious also.

In study group $48.8 \%$ had moderate anxiety, $39 \%$ had severe and $11.4 \%$ had mild anxiety. Only $0.8 \%$ cancer patient had normal anxiety in this group. In comparison group 29.3\% patients were normal in this regard. Majority $(64.7 \%)$ had mild anxiety, $6 \%$ had moderate and no one had severe anxiety. Anxiety status was

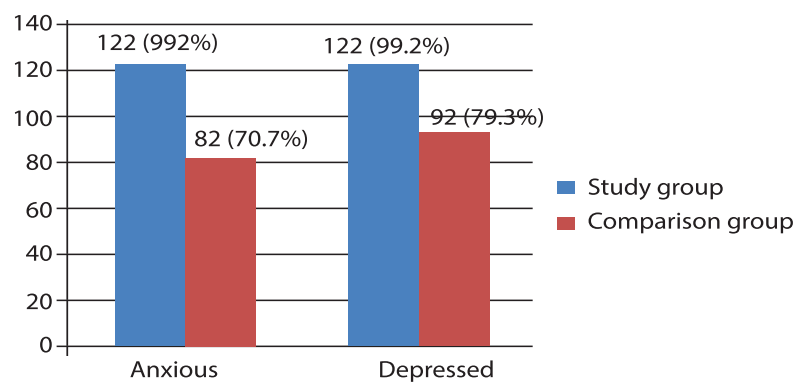

Fig.-2: Psychological distress (anxiety and depression) between the groups

significantly different between the groups ( $\mathrm{p}<$ $0.001)$. Almost all $(99.2 \%)$ the patients in the study group had been found anxious.

Table IV

Anxiety status between the groups

\begin{tabular}{lcccc}
\hline Anxiety Status & $\begin{array}{c}\text { Study } \\
\text { Group (\%) }\end{array}$ & $\begin{array}{c}\text { Comparison } \\
\text { Group (\%) }\end{array}$ & $x^{2}$-Value & $p$-Value \\
\hline Normal (0-7) & $1(0.8)$ & $34(29.3)$ & 162.783 & $<0.001$ \\
Mild (8-10) & $14(11.4)$ & $75(64.7)$ & & \\
Moderate (11-15) & $60(48.8)$ & $7(6.0)$ & & \\
Severe $(16-21)$ & $48(39.0)$ & $0(0.0)$ & & \\
\hline Total & $123(100)$ & $116(100)$ & & \\
\hline
\end{tabular}

Majority of the cancer patients in study group were suffering from depression. In this group $45.5 \%$ had moderate, $37.4 \%$ had severe, $16.3 \%$ had mild depression. In comparison group $62.1 \%$ had mild, $20.7 \%$ normal, $16.4 \%$ moderate and $0.9 \%$ had severe depression. The groups were significantly different $(\mathrm{p}<0.001)$ in depression status.

Table V

Depression status between the groups

\begin{tabular}{lcccc}
\hline Depression Status & Study & Comparison & $x^{2}$-Value & $p$ - Value \\
& Group (\%) & Group (\%) & & \\
\hline Normal (0-7) & $1(0.8)$ & $24(20.7)$ & 111.781 & $<0.001$ \\
Mild (8-10) & $20(16.3)$ & $72(62.1)$ & & \\
Moderate (11-15) & $56(45.5)$ & $19(16.4)$ & & \\
Severe (16-21) & $46(37.4)$ & $1(0.9))$ & & \\
\hline Total & $123(100)$ & $116(100)$ & & \\
\hline
\end{tabular}

Mean anxiety score among male was $15.72 \pm 2.314$ and in female it was $12.06 \pm 2.802$ in study group. The difference between male and female was highly significant $(p<0.001)$; i.e. father with minor children were more anxious than the mother. Female in study group were found more depressed than male $(\mathrm{p}<0.001)$. 
Table VI

Mean score of anxiety and depression between male and female in study group

\begin{tabular}{|c|c|c|c|c|}
\hline \multirow[t]{2}{*}{ Psychological distress } & \multicolumn{2}{|c|}{ Cancer patients in study group } & \multirow[t]{2}{*}{$\mathrm{t}$ - value } & \multirow[t]{2}{*}{$\mathrm{P}$ - value } \\
\hline & Male & Female & & \\
\hline Mean anxiety score & $15.72 \pm 2.314$ & $12.06 \pm 2.802$ & 7.878 & $<0.001$ \\
\hline Mean depression score & $11.91 \pm 2.489$ & $17.55 \pm 2.542$ & 12.211 & $<0.001$ \\
\hline
\end{tabular}

\section{Discussion}

Emotional distress of cancer patients has been widely investigated, and identified as a significant and ongoing problem ${ }^{8}$. In this study 239 cancer patients had been investigated. Of them 123 was in study group and 116 in comparison group. Respondents in study group had underage children. The comparison group had no underage children.

Mean age in study group was $36.97 \pm 4.37$ and in comparison group was $42.98 \pm 11.76$ years. In study group $55.3 \%$ was below 40 years. Whereas $66 \%$ respondents in comparison group was above 40 years. Age of the respondents varied from 20 to 60 years. An estimated $22.4 \%$ of cancer cases occur in individual between 21 and 55 years of age $^{3}$. These are prime child bearing and parenting years. Affected parents may experience heightened distress related to worry about not seeing their children grow up, inability to perform usual parenting activities, the strain of multiple roles while ill, anger or resentment at multiple real or perceived losses and the untimeliness of their illness ${ }^{9}$. In study group $84.6 \%$, and in comparison group $78.4 \%$, cancer patients were married and rest were widow/divorced/separated.

Type of cancer was significantly different between the groups $(p<0.05)$. It was observed that majority participants in both groups had been suffering from guynaecological cancer. $25.2 \%$ in study group and $31 \%$ in comparison group. $2^{\text {nd }}$ highest type was gastrointestinal cancer in study group and haematolymphoid cancer in comparison group. The result could show that the psychological distress could be modulated in cancer patients by cancer type. Other data on this issue showed that women with guynaecological cancer, felt more distressed than patients suffering from other types of cancer ${ }^{10,11}$. The two groups were not significantly different with the distribution of disease duration $(p=0.333)$. Mean duration since diagnosis of cancer was $12.85 \pm 13.107$ months in study group and $11.53 \pm 6.716$ months in comparison group. This is because, only the minimally symptomatic or no symptomatic cancer patients were included in this investigation. Metastasis was absent in majority of respondents $(57.7 \%)$ in study group. In other group $64.7 \%$ had no history of metastasis as well. Appearance of metastasis did not found related with increased distress. However the latter finding needs to be interpreted carefully, because not all patients had documented records whether there was clinical evidence of metastasis at the time of their study participation.

Anxiety prevalence was, $99.2 \%$ in study group and $70.7 \%$ in comparison group. In matter of depression, prevalence was more in the study group as well; i.e. parents with minor children were psychologically more distressed than the other group. This is partly in line with the finding on this issue ${ }^{12}$. Males accounted for $60.2 \%$ respondents in study group $(\mathrm{n}=123)$. And the rest were female. In this group, mean anxiety score among male was $15.72 \pm 2.314$. And in female it was $12.06 \pm 2.802$. This difference between male and female was highly significant $(p<0.001)$; i.e. father with minor children were more anxious than the mother. This finding is contradictory with previous finding on gender-specific experience of distress of cancer patients with minor children. A study observed psychological distress of female partners of cancer patients with underage children (by HADS-D), every second female partner showed clinical anxiety and regarding the degree of depression, between 
the partners there were no differences. With regard to mental distress, a medium correlation was found on the pair level ${ }^{13}$. As per previous findings female gender have been associated with higher emotional distress ${ }^{12,13}$. In another survey, at five universities, (Taking part in the German multisite research project ¿Psychological services of children of parents with cancer supported from 2009 to 2012 by the German cancer aid) on psychological distress in cancer patients with and without under age children, they have found $17.49 \%$ parent in study group with underage children were anxious and majority of them were mother ${ }^{12}$. In this study female in study group were found more depressed than male $(\mathrm{p}<0.001)$. However, psychological distress (anxiety and depression) is modulated in cancer patients by parenthood and gender.

\section{Conclusion}

Almost all of the cancer patients with minor children had been found psychologically distressed. Cancer father with minor children were more prone to development of higher anxiety than the mothers in the same group. Female cancer patients with minor children were found more depressed than male.

\section{References}

1. Billhult A, Segesten K. Strength of motherhood: non recurrent breast cancer as experienced by mothers with dependent children. Scand J Caring Sci.2003;17:22-128

2. Chida Y, Hamer M, Wardle J, Steptoe A. Do stressrelated psychological factors contribute to cancer incidence and survival? Nat Clin Prac Oncol 2008;5:466-75

3. Smith EM, Gomm SA, Dickens CM. Assessing the independent contribution to quality of life from anxiety and depression in patients with advanced cancer. Palliat Med.2003;17:509-513

4. Northouse LL. Breast cancer in younger woman: effects on interpersonal and family relations. $J$ Natl Cancer Inst Monogr.1994;6:183-190
5. Nezu AM, Nezu CM, Felgoise SH and Zwick ML. Psychosocial oncology. In: Handbook of psychology (eds Nezu AM, Nezu CM, Geller PA \& Weiner IB) 2003;pp.267-292. Wiley, New York, NY, USA

6. Andrykowski MA, Carpenter JS \& Munn RK. Psychosocial squeal of cancer diagnosis and treatment. In: Psychosocial treatment for Medical Conditions: Principles and Techniques (eds Schein LA, Bernard HS, Spitz HI \& Muskin PR) 2003;pp.79-131. Brunner-Routledge, New York, NJ, USA

7. Carlson LE, Angen M, Cullum J, Goodey E, Koopman J, Lamont L, Macrae JH, Martin M, Pelletier G, Robinson J, Simpson JSA, Tillotson $\mathrm{L}$ and Bultz BD. High levels of untreated distress and fatigue in cancer patients. British Journal of cancer; 2004;90:2297-2304

8. Helgeson VS, Snyder P \& Seltman H. Psychological and physical adjustment to breast cancer over 4 years: identifying distinct trajectories of change. Health Psychology;2004;23:3-15

9. Robinson KL, McBeth J, MacFarlane GJ. Psychological distress and premature mortality in the general population: a prospective study. Ann Epidemiol. 2004;14:467-72

10. Aass N, Fossa SD, Dahl AA, Moe TJ. Prevalence of anxiety and depression in cancer patients seen at the Norwegian Radium Hospital. Eur J Cancer 1997;33:1597-1604

11. Nordin K, Berglund G, Glimelius B, Sjoden PO. Predicting anxiety and depression among cancer patients: a clinical model. Eur J Cancer 2001; 37:376-384

12. Ernst J, Gotze H, Krauel K, et al. Psychological distress in cancer patients with underage children: gender specific differences. psychoOncology(2012). Published online in Wiley Online Library (wileyonlinelibrary.com). DOI:10.1002/ pon 3070

13. Zabora J, Brintzenhofeszoc K, Carbow B, Hooker C \& Piantadosi S. The prevalence of psychological distress by cancer site. Psycho-Oncology 2001;10:19-28 